\title{
Intracranial angioplasty and stent placement for direct cerebral revascularization of nonacute intracranial occlusions and near occlusions
}

\author{
Clinical article
}

\author{
Max Kole, M.D., ${ }^{1,2}$ Beejal Amin, M.D., ${ }^{1}$ Horia Marin, M.D., ${ }^{2}$ Andrew Russman, D.O., ${ }^{3}$ \\ AND William SANDERS, M.D. ${ }^{1,2}$
}

Departments of ${ }^{1}$ Neurosurgery, ${ }^{2}$ Radiology, and ${ }^{3}$ Neurology, Henry Ford Health System, Detroit, Michigan

\begin{abstract}
Object. The authors reviewed their experience in 7 cases of nonacute intracranial occlusions and near occlusions in which the patients underwent intracranial angioplasty and stent implantation for direct cerebral revascularization.

Methods. Between 2005 and 2008, 4 men and 3 women underwent direct cerebral revascularization of nonacute intracerebral occlusions or near occlusions. Five patients had chronic angiographically documented occlusion and 2 patients had chronic angiographically documented near occlusions. The locations of the treated vessels included 2 supraclinoid internal carotid arteries, 4 middle cerebral arteries, and 1 vertebral artery. Prior to intervention, all patients were symptomatic and experienced strokes ipsilateral to their occlusions. In addition, all patients had clinical or radiographic evidence of ongoing hemodynamic compromise. Five patients underwent successful intracranial angioplasty and stent placement and 2 patients underwent successful intracranial balloon angioplasty alone. The mean time from documented vessel occlusion to treatment was 35 days. All patients had successful revascularization determined using the Thrombolysis in Cerebral Infarction (TICI) scale: TICI Score 3, 2b, and 2a in 4, 2, and 1 patient, respectively, and the mean residual stenosis was $38 \%$.

Results. After uneventful technical procedures, 1 patient suffered a perforator vessel stroke and 1 patient suffered a fatal hemorrhage. Mean modified Rankin Scale score of 2 (range 1-5) and mean Glasgow Outcome Scale score of 4 (range 1-6) were achieved during a mean clinical follow-up period of 399 days (range 1-840 days). Asymptomatic restenosis was documented in 4 patients, 1 underwent bypass retreatment, and 1 patient received repeated balloon angioplasty.

Conclusions. Combined intracranial angioplasty and stent placement is a potential treatment option in selected patients for the direct revascularization of nonacute intracranial occlusions and near occlusions. Whether this represents a substantial risk reduction compared with the best medical therapy or a long-lasting treatment option is unknown. (DOI: 10.3171/2008.12.FOCUS08269)
\end{abstract}

\section{KeY WORDS • chronic occlusion • intracranial angioplasty and stent placement $\quad$ - intracranial atherosclerosis}

$\mathrm{W}$ ITH the advent of intracranial self-expandable stents for neurointerventional use, there has been a widespread increase in the endovascular treatment of patients with intracranial stenosis of 50$99 \%$. Several studies have reported on the feasibility of intracranial angioplasty and stent placement for this indication; $3,9,10,15,32,39,40$ however, no studies have evaluated in-

\footnotetext{
Abbreviations used in this paper: $\mathrm{CBF}=$ cerebral blood flow; $\mathrm{CVR}=$ cerebrovascular reserve; $\mathrm{EC}-\mathrm{IC}=$ extracranial-intracranial; ICA = internal carotid artery; $\mathrm{MCA}=$ middle cerebral artery; MTT $=$ mean transit time; TIA = transient ischemic attack; TICI = Thrombolysis in Cerebral Infarction; VA = vertebral artery; WASID = Warfarin-Aspirin Symptomatic Intracranial Disease.
}

tracranial angioplasty and stenting in those patients with near or complete occlusions ( $>99$ to $100 \%$ ) as well as loss of cerebrovascular reserve, or stage II hemodynamic failure, a group with high risk of future stroke.

Physicians have been reluctant to treat these lesions with angioplasty and stent placement because of technical feasibility, as well as the risk of showering emboli, perforating fragile intracranial arteries, or reperfusing a territory with potential for hemorrhage. This small case series represents a paradigm shift in the way certain selected patients with nonacute near and complete occlusion can be treated. This report also demonstrates the feasibility of directly revascularizing nonacute intracranial occlusions with current technology. 


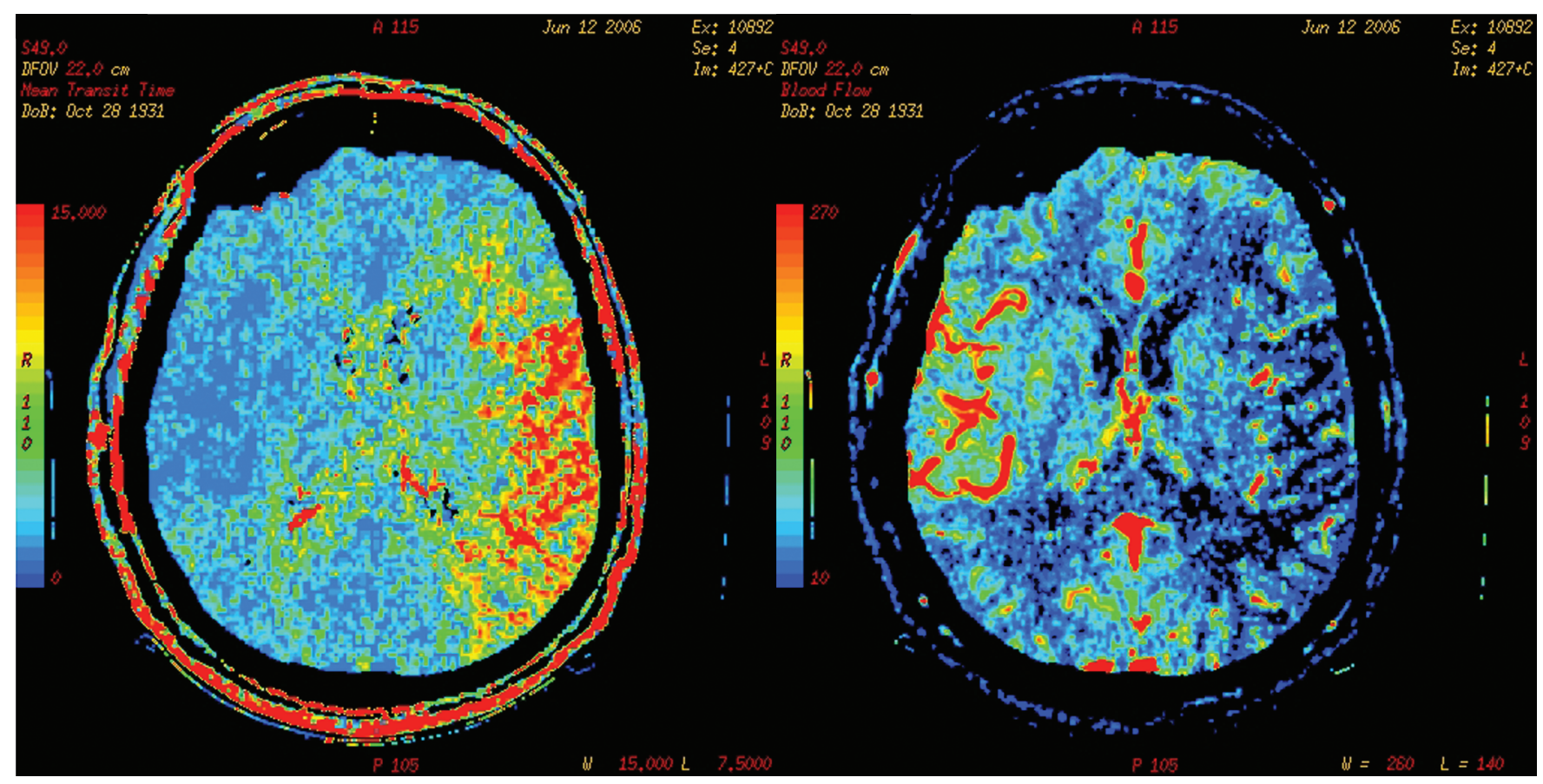

Fig 1. Diamox-based CT perfusion scans obtained in a 74-year-old man with a history of intracranial atherosclerosis and MCA stenosis, on Coumadin since 2001, who presented with recurrent episodes of speech arrest. No evidence of acute infarction was detected on MR imaging. The scan reveal steal phenomenon in the left hemisphere with prolongation of MTT (left) and decrease in the CBF (right).

\section{Methods}

We performed a retrospective chart review (20052008) of all patients treated at our center with angioplasty and/or stent surgery for nonacute intracranial near occlusions or complete occlusions.

\section{Patient Selection}

This method of treatment was reserved for selected patients with documented stroke and progression of symptoms despite the best medical therapy. Hemodynamic TIAs were demonstrated in 3 patients. Loss of cerebral autoregulatory reserve, as demonstrated on CT perfusion scanning with acetazolamide, was observed in 4 patients.

\section{Computed Tomography Perfusion}

Dynamic contrast-enhanced CT perfusion scanning was performed before and after administration of acetazolamide (with $100 \mathrm{ml}$ Optiray-320 contrast and 1 $\mathrm{g}$ acetazolamide in those patients with no obvious clinical signs of hemodynamic failure). Computed tomography perfusion scanning was performed using a standard technique, and functional maps were calculated. Cerebral blood flow, cerebral blood volume, and MTT were calculated by manually drawing regions of interest to avoid areas of infarction and cortical blood vessels. The percentage change for CBF and MTT was calculated: percentage change parameter $=($ the parameter post-acetazolamide administration - the parameter pre-acetazolamide administration)/parameter pre-acetazolamide administra- tion $\times 100$. Deranged CVR was demonstrated as $<30 \%$ increase in CBF and a prolongation of MTT. Computed tomography perfusion scanning before acetazolamide administration demonstrated decreased $\mathrm{CBF}$ and prolonged

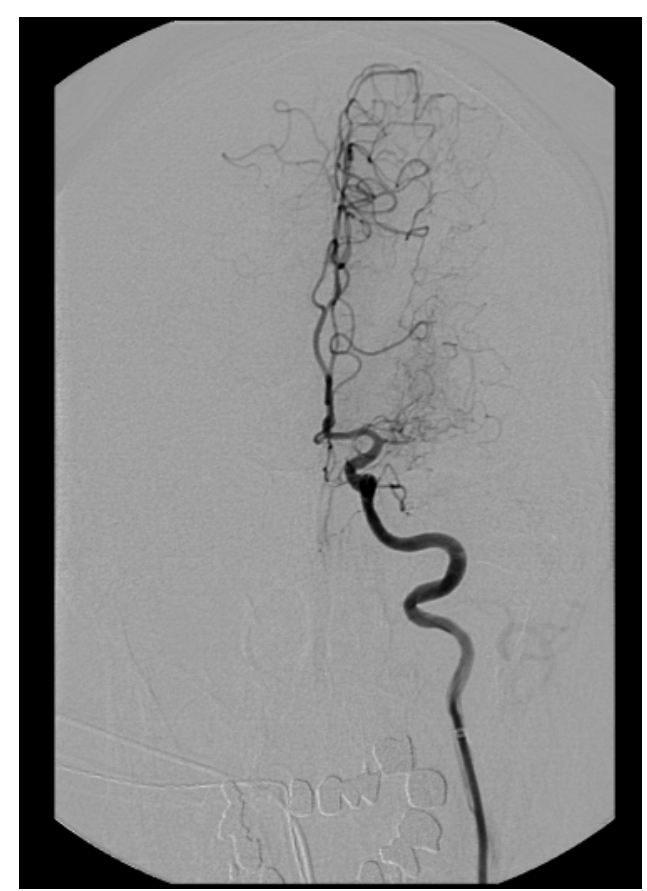

Fig 2. Catheter angiogram demonstrating near occlusion of the left $M_{1}$ segment. A microcatheter with an exchange microguidewire was used to catheterize the left MCA. 


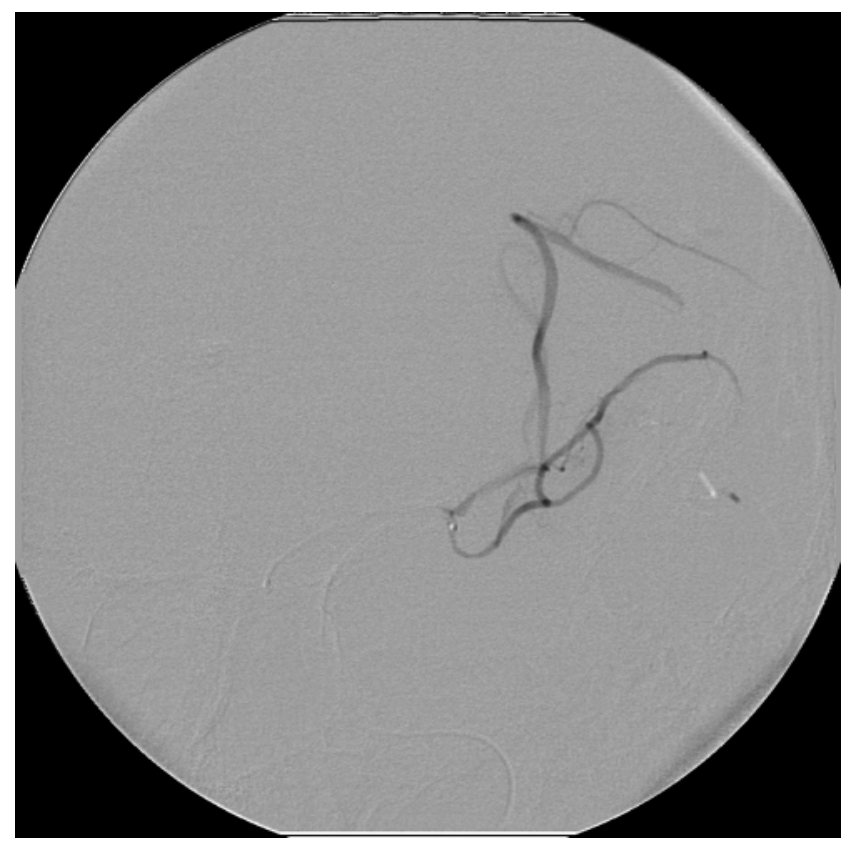

Fig 3. Superselective angiogram demonstrates the anatomy.

MTT in the diseased territories. Derangement of the CVR was classified as mild (10-30\% percentage change), moderate (0-10\% percentage change) and severe (negative percentage change) in CBF (in other words, the steal phenomenon).

\section{Definitions of Complete Occlusion and Near Occlusion}

Complete occlusion was defined by catheter-based angiography as an abrupt cutoff of the index vessel with no continued antegrade flow in the downstream territory or a TICI Scale score of 0 flow. Near occlusion was defined by catheter angiography as stenosis $>99 \%$ with minimal or trickle antegrade flow past the initial obstruction and limited distal branch filling with little or slow distal perfusion (that is, TICI Scale score of 1$).{ }^{16}$ In near occlusion, the caliber of the distal vessel was significantly narrowed and difficult to characterize with the vessel walls collapsed. The standard WASID Trial method was used to measure degree of stenosis. ${ }^{30}$

The term nonacute occlusion or near occlusion was defined as an occlusion or near occlusion well outside the traditional window of opportunity for acute chemical or mechanical thrombolysis, 6-8 hours for an anterior circulation occlusion, and 24 hours for a posterior circulation occlusion. ${ }^{11,14,23,31}$ In all patients the diagnosis of intracranial occlusion or near occlusion was made by catheter angiography before treatment.

\section{Management Options}

The management options, including the risks and benefits of each treatment modality, were reviewed with all the patients. The treatment options included continued best medical therapy with statins and antiplatelet agents, EC-IC bypass if possible, or attempt at direct revascularization with angioplasty and/or stent placement. The patient and family were counseled that both surgical bypass

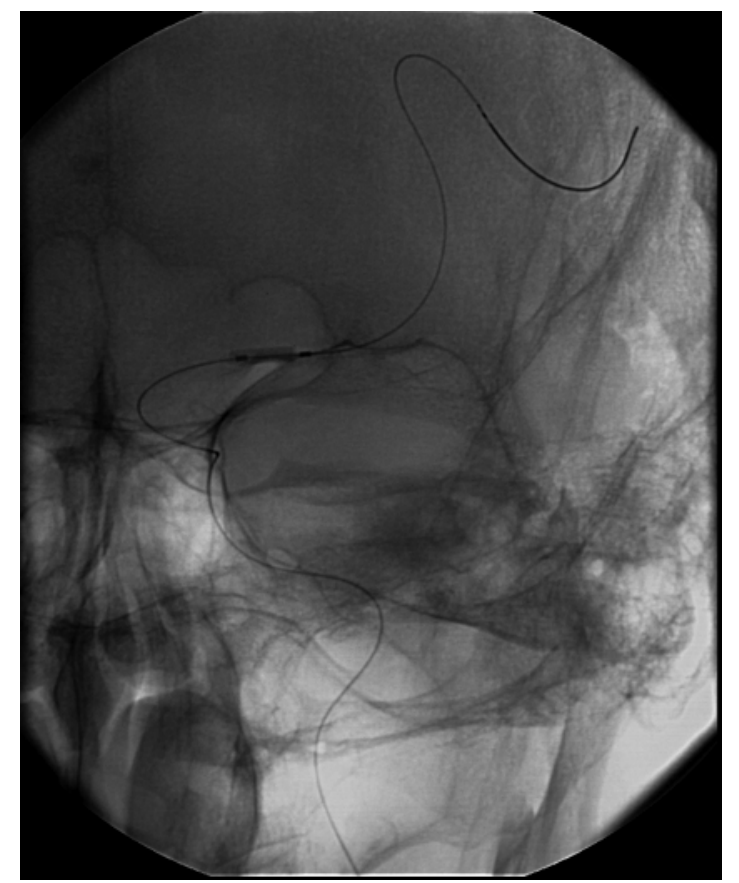

Fig 4. Two balloon inflations were performed with a $2 \times 9-\mathrm{mm}$ Gateway balloon.

and angioplasty/stent placement are considered investigational treatment options. In addition, they were informed that scientific evidence is lacking to support the benefits of intracranial angioplasty and stent implantation compared with best medical therapy or surgical bypass. After multidisciplinary analysis, with the goal of preventing future stroke and minimizing procedural complications, direct revascularization with off-label use of intracranial angioplasty and/or stent placement was recommended in these select patients.

\section{Operative Technique}

The Wingspan stent system was used in compliance with internal review board approval at our center. The endovascular procedures were performed after induction of general anesthesia. All patients were pretreated 5 days prior to the procedure with aspirin ( $325 \mathrm{mg} /$ day) and clopidogrel (75 mg/day or loaded with $600 \mathrm{mg}$ clopidogrel) as well as aspirin (325 mg) 6 hours prior to the procedure. Preprocedural platelet function or platelet inhibition was not tested. The procedures were performed with systemic intraprocedural heparinization, with bolus dose $60 \mathrm{U} /$ $\mathrm{kg}$ followed by $12 \mathrm{U} / \mathrm{kg} /$ hour. A 6 Fr guide catheter was placed in the ICA or VA via a transfemoral approach. Using a coaxial technique with a Prowler (Cordis) or Excelsior SL 10 (Boston Scientific) microcatheter and Agility 0.014 microguidewire (Cordis), the occlusion or near occlusion was gently traversed. In all cases, the occlusions were easily crossed without significant microguidewire manipulation or force. Selective microcatheter injection distal to the occlusion was performed to confirm anatomical position and rule out extravasation, perforation, or dissection. An exchange length 0.014 Transend 300 ES Floppy microguidewire (Boston Scientific) was used to 


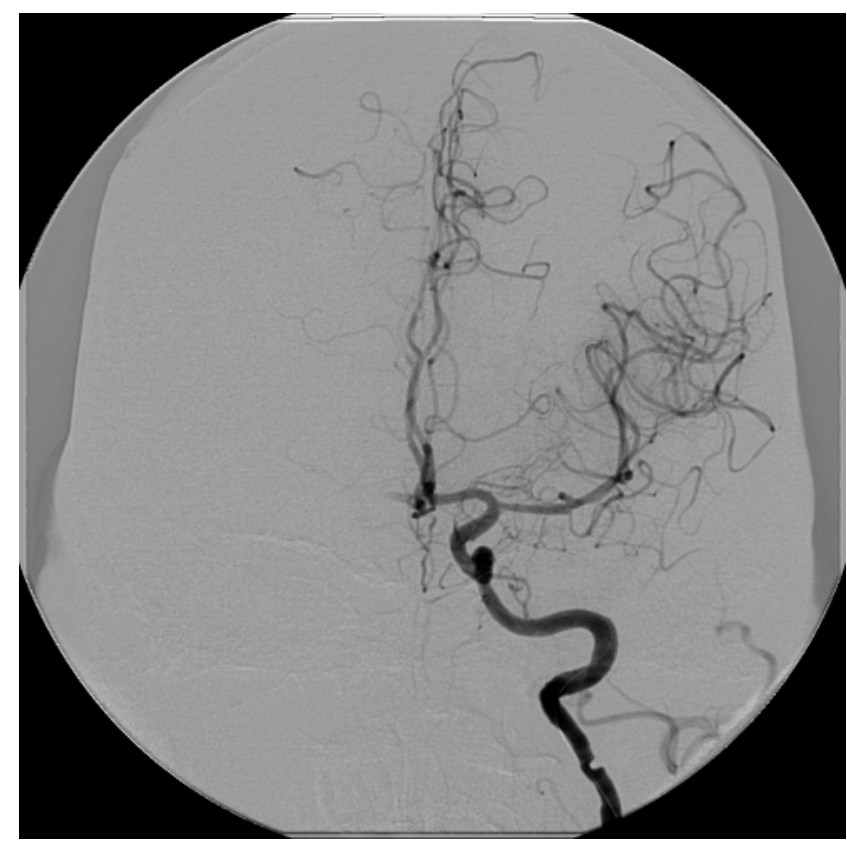

Fig 5. Angiogram obtained after deployment of a $3 \times 15-\mathrm{mm}$ Wingspan stent, showing revascularization of the MCA territory flow (TICl Scale score of 3 ) and $30 \%$ residual stenosis.

exchange the microcatheter for the angioplasty balloon, Gateway (Boston Scientific) or Sprinter (Medtronic), for predilation. The predilation balloon diameter was generally 1.5 or $2 \mathrm{~mm}$ and was purposely undersized. The balloon was then exchanged for the stent system. In 2 cases, balloon angioplasty was performed alone without insertion of a stent. In the case of near occlusion or occlusions, the distal vessel diameter and distal landing zones were often unknown. This information was predicted by the distal microcatheter injection. The stent diameter was generally oversized, usually $0.5-1.0 \mathrm{~mm}$ of the predicted vessel diameter. The proximal one-third to one-half of the stent was positioned at the point of occlusion. As indicated, postdilation of the stent was performed with a balloon sized to $80 \%$ of the predicted vessel diameter. Delayed angiographic runs were performed to rule out thrombosis, spasm, or dissection. The exchange wire and the guide catheter were then removed. The femoral puncture site was closed with the Perclose or Starclose device (Abbott Vascular).

All patients were admitted to the neurointensive care unit for neurological and hemodynamic monitoring. The intraprocedural heparinization was allowed to normalize, and dual antiplatelet agents were continued for a minimum of 3 months.

\section{Clinical Outcomes}

Follow-up information was obtained in each case from postprocedural clinical evaluation and the medical records. The following clinical outcomes were evaluated: any stroke or death within 24 hours and 30 days of the procedure, and ischemic stroke in the territory of the stented artery 30 days postprocedure. Stroke was defined as any hemorrhagic or ischemic event associated with a neurological deficit lasting longer than 24 hours. All procedurally related complications were documented. Technical success of the procedure was defined as improvement of blood flow after balloon angioplasty and/or stent placement across the target lesion. Postprocedural TICI grading was performed. ${ }^{16}$ Preprocedural and postprocedural modified Rankin Scale and Glasgow Outcome Scale scores were assessed., ${ }^{2,18}$ Follow-up angiographic data, as clinically indicated, were collected to estimate the rate of restenosis. Restenosis was defined as $>50 \%$

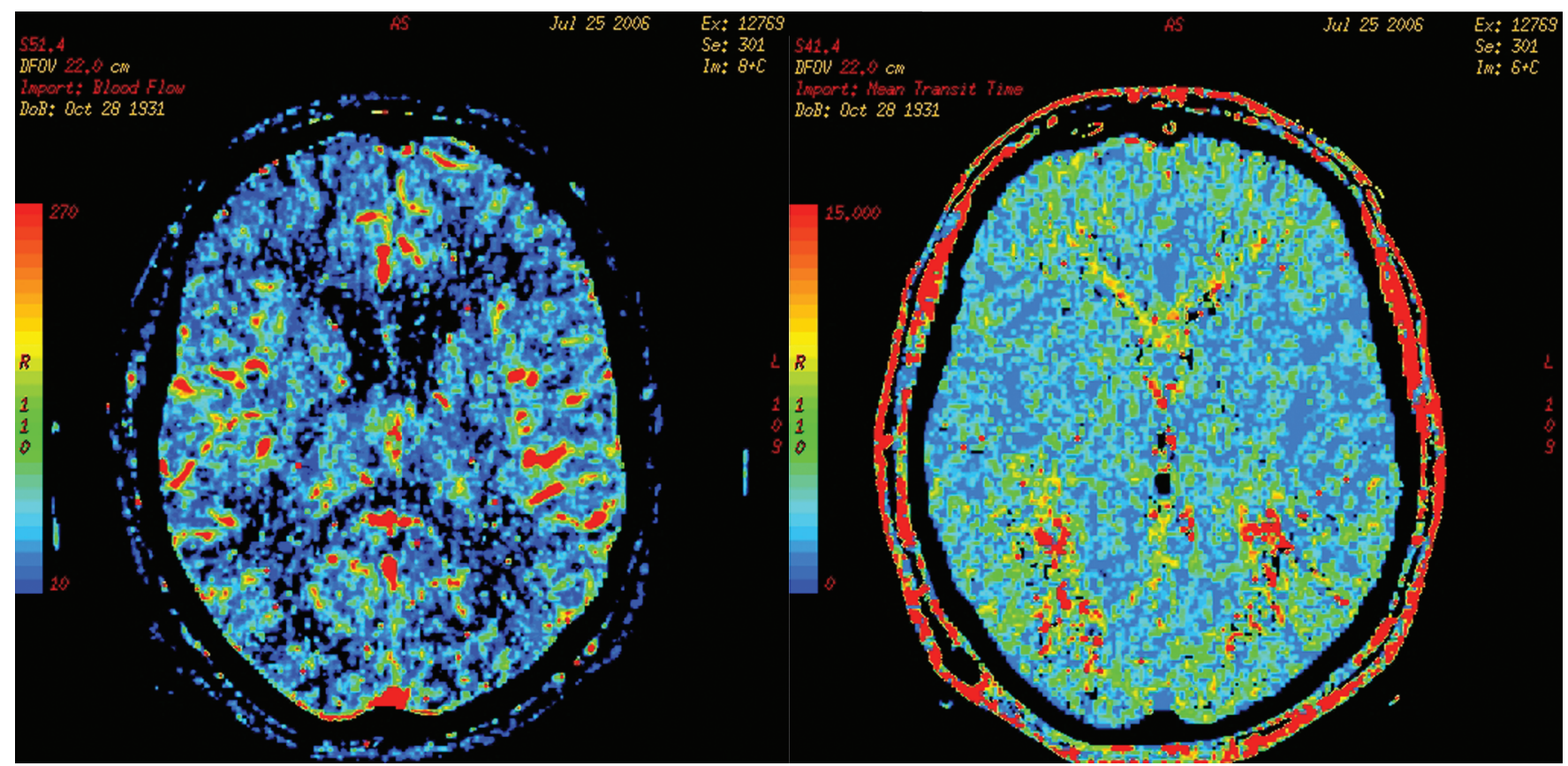

Fig 6. Posttreatment CT perfusion scan demonstrating marked improvement in CBF (left) and MTT (right). 
Direct cerebral revascularization of chronically occluded vessels

TABLE 1: Summary of demographic, treatment, and clinical outcome data

\begin{tabular}{|c|c|c|c|c|c|c|c|c|c|c|c|}
\hline \multirow[b]{2}{*}{$\begin{array}{l}\text { Age } \\
\text { (yrs) }\end{array}$} & \multirow[b]{2}{*}{ Vessel Treated } & \multirow[b]{2}{*}{$\begin{array}{l}\text { Near } \\
\text { Occlu- } \\
\text { sion }\end{array}$} & \multirow[b]{2}{*}{$\begin{array}{l}\text { Occlu- } \\
\text { sion }\end{array}$} & \multicolumn{2}{|c|}{ TICI Score } & \multirow[b]{2}{*}{$\begin{array}{l}\% \text { Re- } \\
\text { sidual } \\
\text { steno- } \\
\text { sis }\end{array}$} & \multirow[b]{2}{*}{$\begin{array}{c}\text { Angio- } \\
\text { plasty } \\
\text { Balloon } \\
(\mathrm{mm})\end{array}$} & \multirow[b]{2}{*}{ Stent $(\mathrm{mm})$} & \multirow[b]{2}{*}{$\begin{array}{l}\% \text { Stenosis } \\
\text { at Follow-Up } \\
\text { (mos) }\end{array}$} & \multirow[b]{2}{*}{$\begin{array}{c}\text { Complica- } \\
\text { tions }\end{array}$} & \multirow[b]{2}{*}{$\begin{array}{l}\text { Retreat- } \\
\text { ment }\end{array}$} \\
\hline & & & & $\begin{array}{c}\text { Pretreat- } \\
\text { ment } \\
\text { Flow }\end{array}$ & $\begin{array}{l}\text { Post- } \\
\text { treat- } \\
\text { ment } \\
\text { Flow }\end{array}$ & & & & & & \\
\hline 66 & It supraclinoid ICA & no & yes & 0 & 3 & 40 & $\begin{array}{c}\text { Gateway } \\
1.5 \times 9\end{array}$ & Wingspan 3 x 15 & $0(14)$ & none & \\
\hline 74 & It $\mathrm{MCA} \mathrm{M}_{1}$ segment & yes & no & 1 & 3 & 30 & $\begin{array}{c}\text { Gateway } \\
2 \times 9\end{array}$ & Wingspan 3 x 15 & $60(14)$ & none & \\
\hline 54 & rt supraclinoid ICA & no & yes & 0 & $2 b$ & 40 & $\begin{array}{c}\text { Gateway } \\
2 \times 9\end{array}$ & Wingspan 4 × 20 & $\begin{array}{l}\text { no follow-up } \\
\text { imaging }\end{array}$ & $\begin{array}{c}\text { cerebral } \\
\text { hemorrhage }\end{array}$ & \\
\hline 41 & It MCA $\mathrm{M}_{1}$ segment & yes & no & 1 & $2 a$ & 0 & $\begin{array}{c}\text { Gateway } \\
1.5 \times 9\end{array}$ & Wingspan 3 x 15 & $\begin{array}{l}\text { no follow-up } \\
\text { imaging }\end{array}$ & acute infarct & \\
\hline 59 & rt MCA $\mathrm{M}_{1}$ segment & no & yes & 0 & 3 & 40 & $\begin{array}{c}\text { Sprinter } \\
2.5 \times 6\end{array}$ & angioplasty alone & $95(11)$ & none & $\begin{array}{l}\text { EC-IC } \\
\text { bypass }\end{array}$ \\
\hline 56 & It VA & no & yes & 0 & 3 & 48 & & Neuroform 4 × 20 & $90(6)$ & none & angioplasty \\
\hline 64 & It $\mathrm{MCA}_{\mathrm{1}}$ segment & no & yes & 0 & $2 b$ & 65 & $\begin{array}{c}\text { Gateway } \\
2 \times 9\end{array}$ & angioplasty alone & $80(4)$ & none & \\
\hline
\end{tabular}

luminal narrowing or interval worsening from immediate posttreatment result (Figs. 1-7).

\section{Results}

Four men and 3 women were included in this study. The mean age was 59.3 years. All patients were symptomatic having experienced documented strokes despite best medical therapy. Clinical or radiological evidence of hemodynamic compromise was suspected in all 7 patients, with angiographically proven occlusion in 5 patients and angiographically proven near occlusion in 2 patients. The treated vessels included 2 supraclinoid ICAs, 4 MCAs, and 1 VA.

Three patients experienced clear hemodynamic symptoms - for example, limb-shaking TIAs or posturally related and reproducible symptoms. Four patients did not have clear hemodynamic events and therefore underwent CT perfusion scanning with and without acetazolamide. In all 4 patients, CT perfusion scanning demonstrated severe derangement of CVR. An underlying focal high-grade intracranial stenosis that led to occlusion or near occlusion was suspected in all patients. Despite proximal intracranial near occlusion or complete occlusion, all patients exhibited some distal collateral flow via leptomeningeal retrograde collaterals, or flow was predicted by preserved neurological function in the downstream territory. All patients treated had chronic occlusions or near occlusions. The mean time from radiographic documentation of occlusion/near occlusion to treatment was 35 days, which most likely underestimated the chronicity of occlusion. Five of 7 patients underwent angioplasty and stent placement. Two of 7 patients underwent angioplasty alone. All patients had successful revascularization with a TICI score of 3 in 4 patients, $2 \mathrm{~b}$ in 2 patients, and $2 \mathrm{a}$ in 1 patient; the mean immediate posttreatment residual stenosis was 38\% (range 0-65\%). One patient suffered a periprocedural perforator vessel stroke, and one patient suffered a fatal hemorrhage several hours after an uneventful technical procedure. No patient experienced a nonprocedurally related ipsilateral stroke or hemorrhage (mean clinical follow-up of 399 days). We performed post-CT perfusion scanning studies in 3 patients, in all of whom significant improvements in $\mathrm{CBF}$ and MTT were observed. Asymptomatic restenosis was documented in $4(57 \%)$ of 7 patients. One of 7 patients underwent retreatment in the form of bypass surgery, and 1 patient underwent repeat angioplasty. Both patients, who initially underwent angioplasty alone, experienced asymptomatic restenosis. A mean posttreatment modified Rankin Scale score of 2 (range 1-6) and mean posttreatment Glasgow Outcome Scale score of 4 (range 1-5) were achieved in a mean clinical follow-up period of 399 days (range 1-840 days). Table 1 provides a summary of the results in our clinical series.

\section{Discussion}

New paradigms for the treatment of selected symptomatic patients with nonacute focal intracranial occlusions need to be investigated. Currently, no consensus exists on the optimal treatment paradigm for severe intracranial atherosclerotic disease.

Since the publication in 1985 of the International Cooperative Study of Extracranial/Intracranial Arterial Anastomosis, a certain therapeutic nihilism has been advocated for nonacute intracranial occlusions. Currently, the Carotid Occlusion Surgery Study is reinvestigating whether EC-IC bypass for indirect cerebral revascularization in patients with symptomatic ICA occlusion and ipsilateral increased oxygen extraction fraction measured by PET will reduce future ischemic stroke. However, this study does not evaluate the treatment of VA, basilar artery, or MCA occlusions and near occlusions. These ter- 


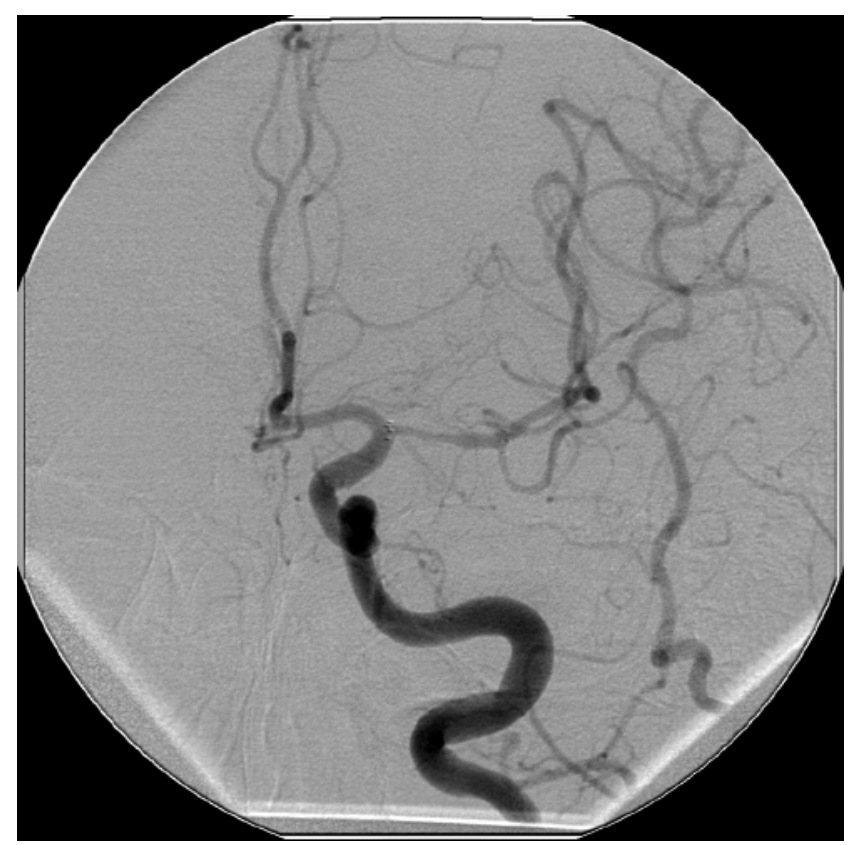

Fig 7. Follow-up angiogram acquired at 14 months revealing $60 \%$ in-stent restenosis. The patient was placed on dual-antiplatelet agents and remains asymptomatic 24 months postprocedure.

ritories are conceivably most suitable for direct revascularization by means of angioplasty and stent placement. Furthermore, there are no published studies on the comparative safety and efficacy of angioplasty and/or stent surgery compared with medical therapy. ${ }^{19}$ Stenting and Aggressive Medical Management for Preventing Recurrent stroke in Intracranial Stenosis (SAMMPRIS), a prospective, randomized multicenter clinical trial funded by the National Institutes of Heath/National Institute of Neurological Disorders and Stroke, is currently investigating medical compared with endovascular angioplasty and stent placement in symptomatic patients with 70-99\% intracranial stenosis.

Angioplasty and stenting of acute intracranial occlusions is emerging as a viable treatment option. In fact, this technique has been shown to result in high recanalization rates with an acceptable degree of safety. Early experience at multiple centers has indicated the feasibility of intracranial self-expanding stents for acute intracranial artery occlusions. In many cases TICI revascularization scores of 2 or 3 have been successfully obtained, often exceeding the recanalization rates currently reported for other means of acute thrombolysis. ${ }^{24}$

This direct revascularization approach involving angioplasty and stent placement in chronically occluded intracranial vessels has not been rigorously investigated or frequently reported. Chronically occluded arteries in the peripheral circulation such as the subclavian artery have been recanalized successfully with this method. ${ }^{4,21}$ Limited case reports have been published regarding recanalizing chronically occluded intracranial vessels. Thomas et al. ${ }^{35}$ recently described 2 cases of chronic extracranial carotid artery occlusions recanalized by angioplasty and stent therapy. In addition, Imai et al. ${ }^{17}$ reported the suc- cessful stenting of the intracranial petrous ICA 7 days after an atherothrombotic occlusion. The authors concluded that short-segment atherothrombotic intracranial ICA occlusions could be opened in the subacute stroke stage without distal migration of thrombi; however, no sizeable reports of direct endovascular revascularization for chronic near or complete intracranial occlusions have been published.

This case series illustrates the potential to open intracranial occlusions well outside the standard accepted time window. The efficacy of thrombolytic treatment in acute ischemic stroke is highly time dependent. Based on current recommendations, intravenous thrombolysis can be administered within 3-4.5 hours of symptom onset, intraarterial thrombolysis within 6 hours of symptom onset, and mechanical thrombolysis up to 8 hours after symptom onset. ${ }^{1,11,13,26,31}$

In this case series, chronic occlusions or near occlusions were demonstrated in all patients, with a mean documented time of occlusion of 35 days. Direct cerebral revascularization was successfully achieved in all 7 patients, illustrating that there is no fixed window of opportunity and considerable variability exists for restoring CBF. The cause of occlusion-acute embolic compared with slowly progressive thrombosis from a tight stenosis-most likely plays an important role in the development of collaterals and influences the window of opportunity for revascularization. In this study, all patients were hypothesized to possess focal stenoses with progressive thrombosis and marginal distal collateral circulation.

Through a better understanding of the natural history of intracranial atherosclerotic disease, ${ }^{29,33,34,38}$ we now know that patients with severe intracranial stenosis and loss of cerebrovascular reserve or Stage II hemodynamic failure have a higher stroke risk. ${ }^{6,12}$ Evidence supports a higher stroke risk in patients with severe stenosis $>70 \%$. The WASID Trial investigators identified subgroups of patients with the highest risk of future stroke. Patients with $>70 \%$ stenosis and recent symptoms are at particularly high risk of stroke. Risk increased linearly with greater percentage of stenosis. The probability of stroke at 1 year $(95 \% \mathrm{CI})$ in patients with $70-79 \%, 80-89 \%$, and 90-99\% stenosis and $100 \%$ occlusion was 17, 31, 5, and $33 \%$, respectively. ${ }^{6,19}$

Several well-designed prospective studies have also shown a strong association between preexisting hemodynamic impairment and stroke risk. ${ }^{6}$ The strongest associations have been found with measurements of oxygen extraction fraction on PET and vasodilatory studies using breath-holding and transcranial Doppler measurements of blood velocity. ${ }^{6,12,19}$ Reduced blood flow and reactivity to acetazolamide have also been shown to be predictive of subsequent ischemic stroke in patients with ICA or MCA occlusion. ${ }^{20}$

Some evidence supports a synergistic effect of embolic and hemodynamic factors. It is likely that preexisting hemodynamic impairment predisposes to ischemic stroke in patients who have an emboligenic, atherosclerotic lesion. Grubb and colleagues ${ }^{12}$ have suggested that either hemodynamic failure predisposes to the formation of thromboemboli or that thromboemboli may cause infarc- 


\section{Direct cerebral revascularization of chronically occluded vessels}

tion more readily in the setting of poor collateral circulation. Others have postulated that hemodynamic failure may lead to delayed washout of microembolic material. ${ }^{5}$ All patients treated in this study were considered to be in these high-risk categories with recent neurological symptoms, severe intracranial stenosis $>99 \%$, or complete occlusion. In 4 patients, acetazolamide-based CT perfusion scanning documented loss of CVR or steal, and 3 patients had characteristic clinical hemodynamic symptoms.

Clearly, not all patients with nonacute intracranial occlusions and near occlusions are candidates for direct endovascular revascularization. Patients with large strokes greater than one-third of the cerebral hemisphere or radiographic evidence of hemorrhagic transformation should not be treated. Patients with arteries thrombosed over a long segment or occluded territories with no distal collateral are also not candidates for direct endovascular revascularization.

Some patients with near occlusions or complete occlusions in whom there is good circle of Willis collateral flow may not need treatment. Rothwell et al. ${ }^{28}$ have demonstrated that patients with extracranial carotid artery near occlusion may not represent a high-risk group. Reports show that benefit in these patients with extracranial carotid artery near occlusion undergoing carotid endarterectomy is marginal in the short term and uncertain in the long term.

However, the natural history of intracranial and extracranial occlusions or near occlusions may be different. Extracranial occlusions have greater capacity for the development of collateral circulation via the circle of Willis. Intracranial occlusions have less ability for the development of collateral flow. In our cases of intracranial near occlusion, the vascular territories tended to be isolated with less opportunity for circle of Willis collaterals and more reliant on leptomeningeal collaterals. This case series illustrates that as the near occlusion or occlusion approaches the target tissue, the hemodynamic consequences are more severe. For example with a $\mathbf{M}_{1}$-segment near occlusion, the circle of Willis collaterals are not available, and the deep perforating vessels have limited potential for collateral flow.

The NASCET (North American Symptomatic Carotid Endarterectomy Trial) angiographic criteria for extracranial carotid artery near occlusions predate modern $\mathrm{CBF}$ perfusion technology and thus represent an anatomic definition without physiologic correlate. ${ }^{25}$ The NASCET angiographic criteria for near occlusion are severe stenosis with evidence of reduced flow in the distal ICA (that is, delayed arrival of contrast into the distal ICA, evidence of collateral flow of contrast medium toward the symptomatic cerebral hemisphere from other arterial territories, or both) and evidence of narrowing of the poststenotic ICA (that is, lumen diameter similar to, or less than, the ipsilateral external carotid artery and less than the contralateral ICA). Subsequently, it has been shown that anatomical imaging studies are not sufficient to determine the hemodynamic status in individual patients. ${ }^{6}$ The presence of complete arterial occlusion does not reliably predict hemodynamic impairment in individual patients. ${ }^{7,27}$ Certain patterns of collateral flow have been correlated with hemodynamic impairment, but the ability of these findings to identify individual patients with hemodynamic impairment has been poor. ${ }^{8,37}$ Thus, in patients without characteristic limb shaking or orthostatic TIAs, which can be associated with hemodynamic impairment, ${ }^{22}$ we relied on additional CT perfusion scanning data to determine the need for intervention. Treatment was reserved for unstable, symptomatic patients with chronic intracranial near occlusion or complete occlusion with steal phenomena when challenged with acetazolamide.

We present, to the best of our knowledge, the first case series on the direct revascularization of intracranial nonacute near and complete occlusions treated with angioplasty and stent therapy. The characteristics of patients amenable to such treatment include symptomatic patients with clinical or radiological evidence of hemodynamic failure and a focal segment of occlusion. This procedure is feasible with current technology. The intraprocedural complication rate is not insignificant and the complications tend to be severe. One patient experienced a perforator stroke presumably from the snow-plowing effect of the balloon angioplasty, and one patient suffered a fatal periprocedural intracerebral hemorrhage. After 30 days, there were no ipsilateral strokes at 1 year. In nearly all the patients with follow-up imaging, restenosis was demonstrated (4 of 7). All patients with restenosis were asymptomatic. Two patients underwent retreatment. The restenosis rate appears to be higher than that in other published series of intracranial angioplasty and stent placement for patients with the traditional 50-99\% stenosis. ${ }^{36,40}$ This can be partially explained by the longer mean follow-up period of 399 days reported in this case series. In addition, a treated near occlusion or complete occlusion may have a higher restenosis rate secondary to the pathological changes in the vessel wall. The direct revascularization achieved through angioplasty and stenting in our series dramatically improved cerebral perfusion and eliminated patients' symptoms in the short term. Prudent follow-up imaging is still warranted.

\section{Conclusions}

Although conclusions drawn from this report are limited by the small number of patients and the inherent flaws of a nonindependently adjudicated retrospective case series, it does represent the largest published patient series concerning the direct revascularization with angioplasty and stenting of chronic intracranial occlusions. This review also demonstrates the technical feasibility of directly revascularizing selected, nonacute intracranial occlusions with angioplasty and stenting well beyond the arbitrary time limits. It also helps define a subgroup of patients with near occlusions or complete occlusions with hemodynamic failure who may be amenable to some type of revascularization treatment. Whether this represents a definitive solution or substantial risk reduction compared with the best medical therapy with antiplatelet agents or statins has yet to be determined by randomized prospective studies. 


\section{Disclaimer}

The authors report no conflict of interest concerning the materials or methods used in this study or the findings specified in this paper.

\section{References}

1. Adams HP, Brott TG, Furlan AJ, Gomez CR, Grotta J, Helgason CM, et al: Guidelines for thrombolytic therapy for acute stroke: a supplement to the guidelines for the management of patients with acute ischemic stroke. Circulation 94:11671174, 1996

2. Bonita R, Beaglehole R: Modification of Rankin scale: recovery of motor function after stroke. Stroke 19:1497-1500, 1988

3. Bose A, Hartmann M, Henkes H, Liv HM, Teng MM, Szikora I, et al: A novel, self-expanding, nitinol stent in medically refractory intracranial atherosclerotic stenoses: the Wingspan study. Stroke 38:1531-1537, 2007

4. Carnevale FC, de Blas M, Merino S, Egana JM: Percutaneous endovascular treatment of chronic iliac artery occlusion. Cardiovasc Intervent Radiol 27:447-452, 2004

5. Derdeyn CP: Mechanisms of ischemic stroke secondary to large artery atherosclerotic disease. Neuroimaging Clin N Am 17:303-311, 2007

6. Derdeyn CP, Grubb RL, Powers WJ: Cerebral hemodynamic impairment: Methods of measurement and association with stroke risk. Neurology 53:251-259, 1999

7. Derdeyn CP, Grubb RL, Powers WJ: Indications for cerebral revascularization for patients with atherosclerotic carotid occlusion. Skull Base 15:7-14, 2005

8. Derdeyn CP, Shaibani A, Moran CJ, Cross DT III, Grubb RL Jr, Powers WJ: Lack of correlation between pattern of collateralization and misery perfusion in patients with carotid occlusion. Stroke 30:1025-1032, 1999

9. Fiorella D, Chow MM, Anderson M, Woo H, Rasmussen PA, Masaryk TJ: A 7-year experience with balloon mounted coronary stents for the treatment of symptomatic vertebrobasilar intracranial atheromatous disease. Neurosurgery 61:236243, 2007

10. Fiorella D, Levy EI, Turk AS, Albuquerque FC, Niemann DB, Aagaard-Kienitz B, et al: US multicenter experience with the Wingspan stent system for the treatment of intracranial atheromatous disease: periprocedural results. Stroke 38:881-887, 2007

11. Furlan A, Higashida R, Wechsler L, Gent M, Rowley H, Kase $\mathrm{C}$, et al: Intra-arterial prourokinase for acute ischemic stroke. The ProACT II study: a randomized controlled trial. Prolyse in Acute Cerebral Thromboembolism. JAMA 282:20032011, 1999

12. Grubb RL, Derdeyn CP, Fritsch SM, Carpenter DA, Yundt $\mathrm{KD}$, Videen TO, et al: Importance of hemodynamic factors in the prognosis of symptomatic carotid occlusion. JAMA 280:1055-1060, 1998

13. Hacke W, Kaste M, Bluhmki E, Brozman M, Davalos A, Guidetti D, et al: Thrombolytics with alteplase 3 to 4.5 hours after acute ischemic stroke. N Engl J Med 359:1317-1329, 2008

14. Hacke W, Zeumer H, Ferbert A, Bruckmann H, del Zoppo GJ: Intra-arterial thrombolytic therapy improves outcome in patients with acute vertebrobasilar occlusive disease. Stroke 19:1216-1222, 1988

15. Henkes H, Miloslavski E, Lowens S, Reinartz J, Liebig T, Kuhne D: Treatment of intracranial atherosclerotic stenoses with balloon dilatation and self-expanding stent deployment (Wingspan). Neuroradiology 47:222-228, 2005

16. Higashida RT, Furlan AJ, Roberts H, Tomsick T, Connors B, Barr J, et al: Technological Assessment Committee of the
American Society of Interventional and Therapeutic Neuroradiology, Technological Assessment of the Society of Interventional Radiology: trial design and reporting standards for intra-arterial cerebral thrombolysis for acute ischemic stroke. Stroke 34:e109-e137, 2003

17. Imai K, Mori T, Izumoto H, Takabatake N, Kuneida T, Yamamoto $\mathrm{S}$, et al: Successful stenting seven days after atherothrombotic occlusion of the intracranial internal carotid artery. J Endovasc Ther 13:254-259, 2006

18. Jennett B, Bond M: Assessment of outcome after severe brain damage. A practical scale. Lancet 1:480-484, 1975

19. Kasner SE, Chimowitz MI, Lynn MJ, Howlett-Smith H, Stern BJ, Hertzberg VS, et al: for the Warfarin Aspirin Symptomatic Intracranial Disease (WASID) Trial Investigators: predictors of ischemic stroke in the territory of a symptomatic intracranial arterial stenosis. Circulation 113:555-563, 2006

20. Kuroda S, Houkin K, Kamiyama H, Mitsumori K, Iwasaki Y, Abe H: Long-term prognosis of medically treated patients with internal carotid or middle cerebral artery occlusion. Stroke 32:2110-2116, 2001

21. Lee PY, Chen WH, Ng W, Lau CP: Percutaneous recanalization of chronic subclavian artery occlusion using optical coherence reflectometry-guided radiofrequency ablation guidewire. Catheter Cardiovasc Interv 60:558-561, 2003

22. Levine RL, Lagreze HL, Dobkin JA, Hanson JM, Satter MR, Rowe BR, et al: Cerebral vasocapacitance and TIAs. Neurology 39:25-29, 1989

23. Levy E, Firlik A, Wisniewski S, Rubin G, Jungreis C, Wechsler $\mathrm{L}$, et al: Factors affecting survival rates for acute vertebrobasilar artery occlusions treated with intra-arterial thrombolytic therapy: a meta-analytical approach. Neurosurgery 45:539548,1999

24. Levy EI, Mehta R, Gupta R, Hanel RA, Chamlzuk AJ, Fiorella D, et al: Self-expanding stents for recanalization of acute cerebrovascular occlusions. AJNR Am J Neuroradiol 28:816-822, 2007

25. Morgenstern L, Fox A, Sharpe B, Eliasziw M, Barnett HJ, Grotta JC: The risks and benefits of carotid endarterectomy in patients with near occlusion of the carotid artery: North American Symptomatic Carotid Endarterectomy Trial (NASCET) group. Neurology 48:911-915, 1997

26. The National Institute of Neurological Disorders and Stroke rt-PA Stroke Study Group: Tissue plasminogen activator for acute ischemic stroke. N Engl J Med 333:1581-1587, 1995

27. Powers WJ, Press GA, Grubb RL Jr, Gado M, Raichle ME: The effect of hemodynamically significant carotid artery disease on the hemodynamic status of the cerebral circulation. Ann Intern Med 106:27-35, 1987

28. Rothwell PM, Eliasziw M, Gutnikov SA, Fox AJ, Taylor DW, Mayberg MR, et al: Carotid Endarterectomy Trialists' Collaboration: analysis of pooled data from the randomized controlled trials of endarterectomy for symptomatic carotid stenosis. Lancet 361:107-116, 2003

29. Sacco RL, Kargman DE, Gu Q, Zamanillo MC: Race-ethnicity and determinants of intracranial atherosclerotic cerebral infarction: the Northern Manhattan Stroke Study. Stroke 26:14-20, 1995

30. Samuels OB, Joseph GJ, Lynn MJ, Smith HA, Chimowitz MI: A standardized method for measuring intracranial arterial stenosis. AJNR Am J Neuroradiol 21:643-646, 2000

31. Smith WS, Sung G, Saver J, Budzik R, Duckwiler G, Liebeskind DS, et al: Mechanical thrombectomy for acute ischemic stroke: final results of the Multi Merci trial. Stroke 39:12051212, 2008

32. The SSYLVIA study investigators: Stenting of symptomatic atherosclerotic lesions in the vertebral or intracranial arteries (SSYLVIA): study results. Stroke 35:1388-1392, 2004

33. The Warfarin-Aspirin Symptomatic Intracranial Disease (WASID) Study Group: Prognosis of patients with symptom- 


\section{Direct cerebral revascularization of chronically occluded vessels}

atic vertebral or basilar artery stenosis. Stroke 29:1389-1392, 1998

34. Thijs VN, Albers GW: Symptomatic intracranial atherosclerosis: outcome of patients who fail antithrombotic therapy. Neurology 55:490-497, 2000

35. Thomas AJ, Gupta R, Tayal AH, Horowitz MB, Jovin TG: Stenting and angioplasty of the symptomatic chronically occluded carotid artery. AJNR Am J Neuroradiol 28:168-171, 2007

36. Turk AS, Levy EI, Albuquerque FC, Pride GL Jr, Woo H, Welch BG, et al: Influence of patient age and stenosis location on wingspan in-stent restenosis. AJNR Am J Neuroradiol 29:23-27, 2008

37. van Everdingen KJ, Visser GH, Klijn CJ, Kappelle LJ, van der Grond J: Role of collateral flow on cerebral hemodynamics in patients with unilateral internal carotid artery occlusion. Ann Neurol 44:167-176, 1998

38. Wityk RJ, Lehman D, Klag M, Coresh J, Ahn H, Litt B: Race and sex differences in the distribution of cerebral atherosclerosis. Stroke 27:1974-1980, 1996

39. Wojak JC, Dunlap DC, Hargrave KR, DeAlvare LA, Culbertson HS, Conners JJ III: Intracranial angioplasty and stenting: long-term results from a single center. AJNR Am J Neuroradiol 27:1882-1892, 2006

40. Zaidat OO, Klucznik R, Alexander MJ, Chaloupka J, Lutsep $\mathrm{H}$, Barnwell S, et al: For the NIH Multi-center Wingspan Intracranial Stent Registry Study Group: the NIH registry on use of the Wingspan stent for symptomatic 70-99\% intracranial arterial stenosis. Neurology 70:1518-1524, 2008

Manuscript submitted November 11, 2008

Accepted December 22, 2008.

Address correspondence to: Max Kole, M.D., Department of Neurosurgery, K-11, Henry Ford Health System, 2799 West Grand Blvd., Detroit, Michigan 48202. email: mkole1@hfhs.org. 